\title{
El ascenso criollo y la construcción de la independencia mexicana, una aproximación genealógica
}

\author{
Juan Fernández Cantero*
}

Recibido el 19 de octubre de 2018; aceptado el 12 de febrero de 2019

\section{RESUMEN}

En el presente ensayo se analizarán dos cartas escritas por Ambrosio Eugenio Melgarejo de Santaella dirigidas al Virrey de Nueva España, el Conde de Aranda y al Rey de España, Carlos III, respectivamente en las que solicitaba los favores reales para dejar a sus hijos "lustrosamente establecido[s]". A partir de la teoría de la genealogía de Foucault, se estudiará el significado de los favores reales dentro del contexto colonial en Nueva España y la importancia del linaje en el establecimiento de una identidad criolla. En estos manuscritos se estudiará en qué medida se da la representación de elementos simbólicos que son clave para la independencia de Nueva España. Además, a partir del estudio de las cartas, se podrá reflexionar sobre el comienzo de algunas de las prácticas que aquejan hoy en día a las sociedades hispanas, tales como son la falta de transparencia de las instituciones públicas o el desequilibrio económico social entre distintos grupos étnicos.

Palabras clave: Ascenso criollo, favores reales, genealogía, identidad criolla, linaje.

* Department of Hispanic Studies, University of Kentucky, Kentucky, Estados Unidos de América, correo electrónico: juan.fernandez@uky.edu 


\title{
The rise of Creole and the construction of Mexican Independence: a genealogical approach
}

\begin{abstract}
This essay analyzes two letters written by Ambrosio Eugenio Melgarejo de Santaella addressed to the Viceroy of New Spain, the Count of Aranda, and the King of Spain, Carlos III, respectively. In such correspondence, Melgarejo requested royal favors to have their children "lustrosamente establecidos" [prestigiously established]. Foucault's theory of genealogy, will shed some light about the meaning of regal concessions within the colonial context in New Spain, and the importance of lineage in the establishment of a creole identity. In the study of Ambrosio's manuscripts there is a representation of symbolic elements that are key to Mexico's independence. In addition, it is possible to study Ambrosio Eugenio's letters as the starting point of some of the practices that afflict Hispanic societies today, such as the lack of transparency of public institutions, or the social, and economic inequalities among different ethnic groups..
\end{abstract}

Key words: Rise of Creole, royal favors, genealogy, Creole identity, lineage.

$\mathrm{E}$ n la colección de documentos relativos a los jesuitas del Archivo Histórico Nacional de Madrid se encuentran varios manuscritos de un criollo de Nueva España que suplica humildemente dos puestos dentro del aparato de la administración política y religiosa del virreinato para así dejar "lustrosamente establecido[s]" ${ }^{11}$ a sus dos hijos. Estos manuscritos son dos cartas de Ambrosio Eugenio de Melgarejo y Santaella, acompañadas por sus correspondientes resúmenes realizados muy probablemente por un funcionario público, con fecha de 28 de marzo de 1769 y dirigidas, respectivamente, al Virrey de Nueva España, el Conde de Aranda, y al Rey de España, Carlos III. Al encontrar estos documentos uno puede preguntarse ¿Qué hacen semejantes peticiones en un legajo de documentos relacionados con los jesuitas?, ¿por qué se decidió archivar estos documentos?, ¿qué relevancia tienen estas cartas dentro del contexto político y social de Nueva España?, ¿quién es Ambrosio Eugenio de Melgarejo y Santaella? y ¿por qué se atrevería a dirigirse al Virrey y al Rey con semejante petición? 
En el presente trabajo se pretende demostrar que más allá de lo anecdótico, las peticiones de Ambrosio Eugenio de Melgarejo y Santaella configuran un modelo óptimo para el estudio de la situación de la burguesía criolla en las décadas previas a la independencia de México. En estos manuscritos se verá que existe la representación de elementos simbólicos que son clave para la independencia de la Nueva España. Además, a partir del estudio de las cartas se podrá reflexionar sobre el comienzo de algunas de las prácticas que aquejan hoy en día a las sociedades hispanas, como son la falta de transparencia de las instituciones públicas o el desequilibrio económico social entre distintos grupos étnicos.

Para el análisis y estudio de los documentos anteriormente indicados se realizará un análisis genealógico foucaultiano. ${ }^{2}$ Este análisis trata de "ir más allá de las 'batallas, decretos, dinastías o asambleas' ${ }^{3}$ para situar el acontecimiento a partir de una diversidad de conjuntos, de capas más o menos profundas, de carácter más o menos decisivo, más o menos raro". ${ }^{4}$ Así, en el desarrollo del presente trabajo se estudiará la correspondencia de Ambrosio Melgarejo teniendo en cuenta la multiplicidad de capas de significación que se extraen del hecho de tal solicitud. En definitiva, mediante el estudio genealógico se pretende crear un discurso sobre las múltiples significaciones a las que se prestan las cartas de Ambrosio Melgarejo, sobre su dinastía, y sobre las consecuencias histórico-sociales que envuelven dichos documentos. Según Foucault "la formación efectiva del discurso: intenta captarlo en su poder de afirmación, y entiendo por esto no un poder que se opondría al de negar, sino el poder de constituir dominios de objetos". ${ }^{5}$ En este caso, las cartas constituyen un objeto idóneo para el análisis genealógico, ya que de acuerdo con Rujas, al hablar de genealogía, Foucault dirige su mirada a aquellos documentos archivados cotidianos, tales como "discursos mercuriales, las actas notariales, los registros de parroquia, los registros portuarios"; 6 estas cartas y sus correspondientes resúmenes notariales bien podrían incorporarse en esta serie de documentos grises, cotidianos, que acumulan polvo en los archivos, que se encuentran "allí donde menos se espera"7 y que pasan desapercibidos.

2 En este artículo se tendrá en cuenta las teorías de la genealogía de Foucault, lo cual permite cuestionar los documentos a analizar dentro del contexto en el que fueron hallados. No ha de confundirse con la genealogía como el estudio del linaje o los ancestros del autor de las cartas objeto de análisis.

Rujas Martínez-Novillo, “Genealogía y discurso. De Nietzsche a Foucault”, p. 12.

Ibid.

Foucault, El orden del discurso, p. 33.

Ibid., p. 46.

Foucault, "Nietzsche, la Genealogía, la Historia", p. 7. 
Los documentos que se estudian seguidamente son cuatro textos que se encuentran depositados en el Archivo Histórico Nacional de Madrid, dentro de la colección de documentos relativos a la Compañía de Jesús. Se trata de dos cartas manuscritas, ambas con fecha de 28 de marzo de 1769, firmadas por Ambrosio Eugenio Melgarejo y Santaella en las que se dirige al Conde de Aranda y a Carlos III, respectivamente, para pedirles que favorezca a sus hijos en el establecimiento de sus carreras profesionales como contraprestación por "el puntual desempeño" 8 de sus labores en la comisión de desmantelamiento del Colegio de San Gregorio de los Jesuitas. El primer texto viene seguido de una breve exposición de motivos que explica y resume dicha carta $;{ }^{9}$ probablemente dicho resumen haya sido realizado por funcionarios cercanos al Virrey, quienes tenían información de primera mano por parte de Ambrosio Melgarejo. Esta suposición de que los funcionarios contaran con información adicional se debe a que en el resumen se incluye información que en la carta no aparece de manera manifiesta; se explica que lo que Melgarejo "suplica humildemente" es "una de las prebendas de esta Iglesia" para el doctor Antonio Eugenio Melgarejo Lobera y una "Plaza Togada [...] en qualquiera de las Audiencias de estos Reynos" ${ }^{10}$ para José Ignacio Melgarejo Lobera. Por tanto, en el resumen se expresa de manera más explícita y en términos funcionales lo que Ambrosio Melgarejo pide al Virrey. La segunda carta de Melgarejo, dirigida a Carlos III, tiene un contenido similar y va acompañada de un resumen. En este caso el resumen funcionarial es más escueto del que acompaña a la carta del Virrey.

Para dar una explicación de por qué Melgarejo tenía la potestad de dirigirse al Rey y qué significado tienen las cartas en un entorno social más amplio, hay que entender primeramente quién fue Ambrosio Eugenio Melgarejo y Santaella y qué lugar ocupaba dentro de la estructura social existente en Nueva España. Bernard Bobb da una visión panorámica de la complejidad social y territorial que componía Nueva España en la segunda mitad del siglo XVIII. Se trataba de una elaborada red estructurada en distintos reinos, provincias, colonias, presidencias, divisiones judiciales y gobiernos locales. La capital, Ciudad de México, era la gran metrópoli del Nuevo Mundo. Respecto al sistema social Bobb explica que la sociedad estaba dividida por una serie de castas bien definidas por el lugar de origen y el grupo étnico. En lo más alto de la pirámide se encontraban los nacidos en España; a éstos les seguían los criollos, blancos nacidos en América, y posteriormente los mestizos, mezcla de blancos e indios. En el nivel inferior de

\footnotetext{
Melgarejo de Santaella, "Carta 1".

Melgarejo de Santaella, "Resumen de Carta 1".

Ibid.
} 
la pirámide se encontraban varios tipos de castas bajas como negros y mulatos, o combinaciones de negros e indios. Respecto a los indios, se les consideraba como una raza aparte y se les otorgaba un perpetuo pupilaje. ${ }^{11}$ Dentro de la estructura en castas se observa una distribución del poder irregular: los nacidos en España eran los que custodiaban los puestos más altos en el virreinato, tanto seculares como religiosos. En la mayoría de los casos los puestos de virreyes, gobernadores, jueces, obispos y arzobispos estaba en manos de los españoles. Bobb explica que en la segunda mitad del siglo XVIII, aunque estaban en minoría numérica, los españoles protegían celosamente su supuesta superioridad no sólo frente a los criollos, sino también con respecto a sus propios hijos. Respecto a los criollos, éstos estaban condenados a ser congénitamente inferiores por el efecto despectivo que tenía el haber nacido en tierras de ultramar. Los criollos ocupaban cargos eclesiásticos y administrativos de menor rango, lo que les llevó a un "bitter resentment for the system which artificially and urneasonably placed them in the category of second-class human beings" 12 [un amargo resentimiento hacia el sistema, el cual de manera artificial y sin razón, les situaba como seres humanos de segunda categoría]. ${ }^{13}$ A los criollos no les bastaba haber heredado grandes latifundios o atesorar lujos y riquezas para calmar su frustración ante la injusticia social que padecían respecto a los nacidos en Europa, pues anhelaban formar parte de las más altas estructuras de poder del lugar en el que habían nacido.

Del autor de los textos objeto de estudio, Ambrosio Melgarejo Santaella, se sabe que nació en Santiago de Guatemala en 1713 y que escribió las cartas cinco años antes de su muerte, en $1774 .{ }^{14}$ Ambrosio era un criollo cuyos orígenes se remontaban varias generaciones atrás en América. Se sabe que su abuela paterna, Josefa Aponte Fernández Poveda de la Torre, nació en La Habana, y junto con su abuelo, Baltasar Santaella Melgarejo, tuvieron en Cuba a su padre, Ambrosio Tomás Melgarejo Santaella. La abuela materna de Ambrosio Melgarejo también había nacido en tierras americanas, en Ciudad de México. ${ }^{15}$ Todo este linaje demuestra que el autor del manuscrito portaba una larga tradición criolla bien asentada en Nueva España. Carlos Garriga afirma que las élites criollas utilizaban el término "españoles americanos" ${ }^{16}$ para autodenominarse, esto es, americanos de origen exclusivamen-

11 Bobb, The Vice-regency of Antonio Maria Bucareli in New Spain, 1771-1779, p. 5.

Ibid.

3 Las traducciones están hechas por el autor del artículo.

14 Sanchiz y Gayol, "Seminario de Genealogía Mexicana”, https://es.geneanet.org, [consultado el 1 de octubre de 2018].

15 Ibid.

16 Garriga, "El patriotismo criollo entre Nueva España y México", p. 84. 
te español. Además, Ambrosio Melgarejo ocupaba un puesto de gran influencia dentro del virreinato; en la segunda carta que se estudia, dirigida a Carlos III, Melgarejo se identifica como "Oydor de la Audencia de México". Ramos-Kittrell afirma que Ambrosio Melgarejo era "mayor and judge of the supernumerary crime court of Mexico"17 [alcalde y juez del juzgado criminal supernumerario de México]. Otra fuente, Mucio Martínez ofrece un relato detallado de su trayectoria profesional en el virreinato, al decir que Ambrosio era "del Consejo de su Magestad su Oidor en la Real Audiencia de esta Nueva España y Juez Privativo de ventas y composiciones de tierras y aguas baldías ó realengas en el Distrito de dicha Real Audiencia por su Magestad que Dios guarde etc.". ${ }^{18}$ En cualquier caso, todo apunta a que se trataba de un personaje de gran influencia en la corte virreinal y con un considerable poder político.

Respecto a sus hijos, José Ignacio y Antonio Eugenio, para quienes Ambrosio pedía "Plaza de Indias" y una "prebenda en México" respectivamente, se sabe que el primero de ellos era licenciado ${ }^{19}$ y el segundo era doctor por la Real y Pontificia Universidad de México y ocupó el cargo de rector de la misma. Debido a los puestos de responsabilidad que ocupaba tanto Ambrosio Melgarejo como sus hijos y el alto nivel de educación que ostentaban, se puede afirmar que se trataba de una familia criolla ilustrada. En el segundo volumen del Diccionario universal de historia y geografía se ofrece una extensa biografía de Antonio Eugenio Melgarejo Santaella y Lobera en la que se detalla que fue clérigo presbítero del arzobispado de Ciudad de México, "abogado de la real audiencia y de presos", "secretario del santo oficio", rector, inquisidor con voto y asesor de cuatro virreyes, además de una larga descripción de su intensa carrera política, religiosa y docente. ${ }^{20}$

De la información sobre Antonio Eugenio Melgarejo que se ofrece en el Diccionario universal se extraen importantes datos a tener en cuenta. El primero de ellos es que el hijo de Ambrosio acaparó una importante influencia y poder dentro del virreinato, superando incluso el ya amasado por su padre. La influencia de Antonio Eugenio se extendía a asuntos terrenales y divinos. En los asuntos terrenales ejercía su poder político como asesor de virreyes y como rector universitario, mientras que en los asuntos religiosos ejercía su poder político a través de la inquisición, y muy notablemente, mediante su prebenda en la real colegiata, lo que hoy se conoce como la

19 Sanchiz y Gayol, "Seminario de Genealogía Mexicana", https://es.geneanet.org, [consultado el 1 de octubre de 2018].

20 Diccionario universal de historia y geografia, pp. 394-395. 
Basílica de Santa María de Guadalupe. ${ }^{21}$ Es interesante la posición de Antonio Eugenio como criollo situado en las altas esferas; también, para el propósito de este artículo, es necesario pensar en la huella que dejó en las futuras generaciones de criollos novohispanos que estudiaron en las universidades de la metrópoli, ya que ejerció como rector dos veces de la Universidad de México y fue el creador de las constituciones del Colegio de San Ildefonso en 1777. En el Diccionario universal de historia y geografia, publicado en 1853, más de un siglo después de su nacimiento, todavía se elogiaban los progresos literarios que los colegiales habían experimentado hasta la fecha como consecuencia de su intervención universitaria. ${ }^{22}$ Además, también se puede comprobar que, en efecto, las cartas de Ambrosio Melgarejo tuvieron el fin deseado en el caso de la petición para beneficio de su hijo Antonio Eugenio; éste consiguió la codiciada prebenda en la iglesia metropolitana, no de manos del Conde de Aranda, sino del virrey sucesor, Antonio María Bucareli. No cabe duda de que Antonio Eugenio Melgarejo llegó a ser una de las personas más influyentes de Nueva España en el siglo XVIII.

Para terminar el análisis de la actuación de Antonio Eugenio es interesante reflexionar sobre el papel de los jesuitas en este contexto. En primer lugar, la razón principal por la que Ambrosio Melgarejo pide los favores reales es por labor en "la Commision sobre el extrañamiento, ocupación de Temporalidades pertenecientes a los Regulares Jesuitas del Collegio de San Gregorio de esta Capital". ${ }^{23}$ Ambrosio Melgarejo tuvo un papel activo en la expulsión de los jesuitas en Ciudad de México, siguiendo los mandatos de Carlos III. Por otro lado, en la cita arriba expuesta se hace especial mención a Antonio Eugenio Melgarejo como primer rector del Colegio de San Pedro y San Pablo y San Ildefonso tras habérselo arrebatado a los jesuitas con las Temporalidades. Pese a que los Melgarejo estaban bien integrados en las élites del gobierno virreinal sería válido preguntarse hasta qué punto estaban de acuerdo con la política de Carlos III referente al extrañamiento de los jesuitas. Ésta es una duda más que razonable teniendo en cuenta el estudio de Torales Pacheco sobre los jesuitas y la independencia de México en el que se afirma que los jesuitas hasta mediados del siglo XVIII mantenían vínculos muy estrechos a las élites agrarias, mineras y mercantiles y se "preciaba de su identidad criolla y de su fortaleza espiritual". ${ }^{24}$ Respecto a la

21 Ibid.

22 Ibid.

23 Melgarejo de Santaella, "Carta 2".

24 Torales Pacheco, "Los jesuitas y la independencia de México: algunas aproximaciones”, p. 399. 
población de egresados universitarios que estudiaron en el Colegio de San Ildefonso durante el mandato borbónico, el mismo colegio universitario que fue posteriormente asignado a Antonio Eugenio Melgarejo, "el 95 por ciento de los colegiales eran criollos o nacidos en diferentes intendencias del territorio novohispano"; ${ }^{25}$ dichos colegiales como criollos de primera generación de familias que buscaban ascenso social y de orígenes rurales y mineros. ${ }^{26}$ Desde luego, los jesuitas socialmente constituían un peligro para Carlos III y no sólo por su influencia educativa; Torales Pacheco identifica "su saber corporativo y sus vínculos transoceánicos a la par de los de las élites de cara a la modernidad" 27 como los principales motivos de sospecha por parte de los estados absolutistas del siglo XVIII.

Precisamente, por esta razón, no es de extrañar que se documentara todo lo referente a este grupo religioso y muy particularmente el proceso de desmantelamiento tras la expulsión. Las cartas de Melgarejo de Santaella forman parte de un dossier relativo a las Temporalidades de los jesuitas. Desde un punto de vista genealógico los manuscritos dirigidos al Virrey y al Rey, dentro del contexto en el que fueron archivados, no son más que evidencias que sirven para testificar el proceso de desamortización jesuita, documentos que en la época en la que fueron producidos tenían un carácter ordinario y burocrático. Según Ann Stoler, los archivos coloniales, como podría serlo considerado en este caso el Archivo Nacional de Madrid, son un reflejo de la "esencia verdadera de la política colonial", ${ }^{28}$ pues demuestran a través de los artefactos que se conservan cuáles eran los sistemas de valor y los acontecimientos relevantes para la colonia. Así, mientras las cartas que aquí se analizan son una parte integrante del dossier sobre los jesuitas, no son más que una prueba que forma parte de una cuestión, la jesuítica, que en aquellos momentos preocupaba a la corona y merecía ser extensamente documentada. En las cartas que escribe Ambrosio Melgarejo al Virrey y al Rey, respectivamente, el principal motivo para pedir los favores reales es que estuvo "al cuidado" 29 de la comisión "sobre el extrañamiento, y ocupación de Temporalidades pertenecientes a los Regulares Jesuitas del Collegio de San Gregorio de esta Capital". ${ }^{30}$ Además, aunque en la carta al Virrey no lo escribe, Ambrosio sí hace saber al Rey que ha estado trabajando en la Audiencia de

Hidalgo Pego, Reformismo borbónico y educación. El colegio de San Ildefonso y sus colegiales (1768-1816), p. 162.

26 Ibid.

${ }^{27}$ Torales Pacheco, "Los jesuitas y la independencia de México: algunas aproximaciones", p. 399.

28 Stoler, "Archivos coloniales y el arte de gobernar", p. 470.

29 Melgarejo de Santaella, "Carta 2".

30 Ibíd. 
México por 27 años. Ambrosio hace uso de ambos datos autobiográficos para mostrar al Rey su alta fidelidad a la corona, no sólo a lo largo del tiempo, sino también en las últimas políticas llevadas a cabo para expulsar a los jesuitas; esto lo hace con el claro objetivo de conseguir los favores reales. Respecto a las peticiones que realiza Ambrosio para sus hijos, una lectura contemporánea podría dar lugar a suponer que se trataba de un caso de corrupción. Michel Bertrand estudia el significado de la palabra corrupción dentro de la Real Hacienda Novohispana de los siglos XVII y XVIII. Según Bertrand no sería preciso aplicar el término corrupción en el contexto virreinal ya que se estaría tratando de imponer un concepto actual en un contexto histórico diverso. En este caso, los favores que solicita Ambrosio no se podrían calificar como corrupción ya que él no ejerce sus servicios a favor de un Estado, lo cual es un concepto del siglo XIX, sino al Rey, su Señor. ${ }^{31}$ Bertrand afirma que "el beneficio de los cargos no necesariamente o automáticamente implicaba corrupción, sobre todo cuando los disfuncionamientos de la administración podían tomar muchas otras formas que la de abusos asociados al beneficio de los cargos de gobierno", ${ }^{32}$ lo que es decir, que la venalización de cargos o la petición de favores reales para ocupar puestos públicos era una práctica que entraba en los esquemas de la moralidad en el contexto histórico virreinal. Los abusos de poder, más cercanos al concepto de corrupción en el virreinato, estarían relacionados con el orden moral o religioso debido a que la sociedad estaba supeditada a los valores provenientes del cristianismo. ${ }^{33}$ Dichos comportamientos están legitimados desde "lógicas ajenas al Estado moderno"; 34 éstas se basarían en conceptos tales como la fidelidad al Rey, a la corona, o al gobierno o las estrategias familiares. Sin duda, Ambrosio Melgarejo deja bien fundamentadas las peticiones que hace en sus cartas basándose en la lógica reinante.

Al manifestar al Virrey la "verdadera inclinación que [le] he tributado siempre á las glorias de su nombre; I confiado en la notoria integridad" y al asegurarse de que el Rey sabe de las "fieles dedicaciones" que ha realizado y las "justissimas y bien premeditadas intenciones" ${ }^{35}$ con las que se presenta, lo que hace Ambrosio Melgarejo es desplegar su capacidad de negociación para conseguir tan codiciados favores. Ambrosio debió de ser un personaje con una gran influencia en la corte virreinal ya que, al menos parcialmente, ${ }^{36}$

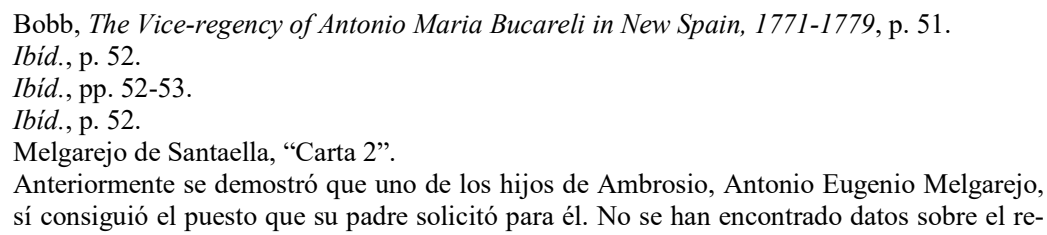


consiguió los favores requeridos en un momento en el que el poder negociador se comenzaba a limitar con las reformas autoritarias de los Borbones. No existe, por tanto, una relación directa entre corrupción y la venalidad de cargos públicos y el favoritismo con la pérdida del virreinato por parte de España, más bien es el autoritarismo borbónico lo que hace surgir la "crisis del orden imperial importada desde la metrópoli"; ${ }^{37}$ a esto se le ha de sumar también la complejidad que le suponía a la corona administrar unos territorios tan estructuralmente complicados como lo eran los novohispanos desde la otra parte del océano. Todo esto se ve metafóricamente representado en el archivo colonial. Las cartas dentro del dossier al que pertenecen no son más que pruebas que ayudan a documentar hechos que la corona consideraba espinosos o importantes, como lo fue la expulsión de los jesuitas.

El mismo Conde de Aranda, Virrey de Nueva España, a quien iba dirigida la primera de las cartas de Ambrosio Melgarejo, advierte del alto riesgo que tiene la corona de perder las posesiones de ultramar. Esto lo explica López Escudero en El supuesto memorial del Conde Aranda sobre la Independencia de América.$^{38}$ Este memorial, que data de 1783, lo habría escrito el Conde de Aranda cuatro años después de dejar su puesto como virrey de Nueva España. En éste el Conde de Aranda debate sobre las consecuencias que la Independencia de Estados Unidos podría tener en la colonia y el papel que tuvo España al contribuir a tal movimiento independentista. Por un lado, Aranda explica la necesidad de luchar junto a Francia en contra de Inglaterra, pero por otro lado, manifiesta su intranquilidad de cara a posibles movimientos independentistas en las colonias españolas. Para desarrollar su preocupación sobre la independencia de las colonias españolas, en buena parte de dicho memorial el Conde trata sobre "las dificultades de que España pueda mantener a la larga su dominio en América, habida cuenta de que todos los problemas - incluidos abusos y mal gobierno - resultan potenciados y de muy difícil remedio por la enorme distancia existente entre esos territorios y la metrópoli". ${ }^{39}$ Estas distancias que se mencionan no sólo eran físicas, Garriga advierte de la nefasta influencia que tuvo para la metrópoli las distancias legales. En los territorios americanos se intentó instaurar el mismo sistema legal que en Castilla, sin embargo, con el devenir del tiempo éste se volvió inefectivo en el Nuevo Mundo por las peculiaridades estructurales. La diferenciación legal americana respecto a la castellana fue conse-

sultado de la petición referente al otro hijo, José Ignacio Melgarejo, para el que se pedía una Plaza de Indias.

7 Bobb, The Vice-regency of Antonio Maria Bucareli in New Spain, 1771-1779, p. 62.

8 Escudero, El supuesto memorial del Conde de Aranda sobre la independencia de América.

9 Ibid., p. 27. 
cuencia de leyes creadas para regular elementos excepcionales; se instauraron disposiciones legales que hubieran sido imposibles de implantar en Castilla de acuerdo con su constitución legal tradicional. ${ }^{40}$

Pese a que Bertrand afirma que el beneficio y la venta de oficios públicos es una práctica normal dentro del virreinato y no tiene acción directa en el germen de la independencia, Garriga ofrece una visión totalmente contrapuesta al hablar de excepcionalidad legal americana frente a la metrópoli. Dentro de las diferencias existentes entre los dos sistemas legales se encuentra de manera sobresaliente el funcionamiento que tenía el beneficio y la venta de oficios públicos en cuanto al racionamiento discursivo que poseían estas acciones en un territorio y el otro. Este hecho se relaciona con la creación de una América política, lo cual creó un ambiente propicio para la crisis de 1808. Para Garriga el derecho de prelación fue esencial para la creación de un espacio político para las patrias criollas. Este derecho de prelación hacia que los españoles criollos tuvieran preferencia para ocupar los puestos de las magistraturas superiores en América basando su alegato en un discurso jurídico:

Bajo la forma de representaciones o memoriales elevados al monarca por letrados que, en su condición de criollos y a nombre propio o/y de las corporaciones a las que pertenecían, pedían cargos (oficios y beneficios), el discurso criollo era primero que nada un discurso jurídico, como correspondía a un mundo que, por su manera de estar constituido, confundía identidad y derecho propio. ${ }^{41}$

De esta manera, volviendo la vista al objeto de estudio, las cartas de Ambrosio Melgarejo, se puede observar que éste estaba haciendo uso de su derecho de prelación en favor de sus hijos. Ambrosio Melgarejo alegaba en su carta al Rey los 27 años trabajados en la Audiencia de México. En la colonia, las personas que trabajaban en las Audiencias, como Ambrosio, tenían una influencia muy elevada en la corte, pues se les consideran como "personas desdobladas del rey para la justicia y el gobierno del territorio, en la economía institucional americana". ${ }^{42}$ La ocupación de estos cargos era muy competitiva. Es precisamente un cargo en la Plaza de Indias lo que reclamaba Ambrosio Melgarejo para su hijo José Ignacio.

Las cartas de Ambrosio Melgarejo formarían parte de todo un discurso jurídico ya establecido y respetado por la corona iniciado por el abogado novohispano, Juan Antonio de Ahumada. Garriga estudia en profundidad la

40 Garriga, "El patriotismo criollo entre Nueva España y México", pp. 93-94.

Ibid., p. 98.

Ibid., p. 94. 
Representación político legal a nuestro señor soberano de Ahumada, donde se situarían las bases filosófico-jurídicas de la legitimación para la ocupación de los puestos de poder más relevantes de la América colonial por parte de los criollos españoles americanos. Dichas bases alegarían el apego a la tierra y el haber nacido en América como condición natural para gobernar los territorios. Además, al ser naturales americanos, los criollos estarían más cerca de alcanzar el bien común, pues son conocedores de las características histórico-geográficas y estructurales del territorio. En esta línea se interpreta el texto de Ahumada para encontrar las equiparaciones "tierra-patria" y "comunidad-república" 43 que sustentarían los movimientos independentistas del siglo siguiente. Los criollos de las clases elevadas se reafirman como abanderados de la identidad americana; esta identidad se forja a través del ya mencionado derecho de prelación. Además, tomando como modelo las cartas de Melgarejo de Santaella, desde la óptica de la genealogía de Foucault se observa la miopía del aparato colonial para identificar el ejercicio del derecho de prelación como una posible amenaza a la integridad de los territorios de la corona.

Las convenciones archivísticas se basaron en un conjunto cambiante de verdades coloniales acerca de lo que debe clasificarse como secreto y asunto de seguridad de Estado y qué acciones se podrían descartar como aquellas que incitan a la cólera ad hoc o que se deban reconocer como subversión contra el Estado. ${ }^{44}$

Entendiendo las cartas dentro de su contexto y por cómo fueron archivadas, el derecho de prelación se categorizaba en la colonia como un proceso burocrático y no formaba en sí un área taxonómica al carecer de la atención monárquica.

Finalmente, hay que tener en cuenta la intensificación del proceso constructivo del sentimiento patriótico criollo en la segunda mitad del siglo $\mathrm{XVIII},{ }^{45}$ justo en el mismo marco temporal en el que se realizan las cartas de Ambrosio Melgarejo. De hecho, dos años después de la redacción de dichas cartas se da en la capital mexicana la Representación que hizo la Ciudad de México al rey don Carlos III en 1771 sobre que los criollos deben ser preferidos a los europeos en la distribución de empleos y beneficios de estos reinos ${ }^{46}$ En este escrito los criollos bien establecidos en la sociedad de Nue-

43

45 Ibid., p. 110.

46 "Representación que hizo la Ciudad de México al rey don Carlos III en 1771 sobre que los criollos deben ser preferidos a los europeos en la distribución de empleos y beneficios de estos reinos", 500 años de México en documentos, 
va España exponen al Rey la necesidad de no ser discriminados respecto a los españoles europeos en cuanto a la ocupación de altos cargos en la administración: "días ha que reflejábamos, no sin el mayor desconsuelo, que se habían hecho más raras que nunca las gracias y provisiones de vuestra majestad a favor de los españoles americanos, no sólo en la línea secular, sino aun en la eclesiástica". ${ }^{47}$ El resto del texto sigue la misma retórica de lamentación al Rey por la desigualdad de trato. En el texto también se desarrolla la afirmación de los valores monárquicos y españoles y la petición de restauración de la dignidad de los españoles americanos a través del reconocimiento de la aptitud para desempeñar las tareas gubernamentales más elevadas. Del extracto anterior de la Representación... se observa la reclamación de puestos de autoridad civiles y religiosos; de la misma manera, dos años antes de la Representación... Ambrosio Melgarejo reclama para sus hijos, José Ignacio y Antonio Eugenio, puestos de la más alta responsabilidad civil y religiosa en sus misivas.

Como se ha podido comprobar en las páginas anteriores, desde una perspectiva genealógica, la importancia de las cartas de Ambrosio Melgarejo radica en la información que el objeto en sí ofrece contextualizado. Más allá de lo anecdótico, los requerimientos al Rey formaban parte de una retórica jurídica establecida durante el siglo XVIII que estaba fundamentada en un proyecto más amplio de autorrepresentación y autogobierno por las clases criollas de ascendencia europea, los llamados españoles americanos. Estas clases criollas compartían el amor a la patria, tanto la madre patria como las respectivas patrias americanas y el amor a la comunidad, a aquellos nacidos en los territorios americanos, y reclamaban el derecho a promocionarse y ser reconocidos.

Además, en las cartas de Melgarejo se observa la petición de cargos públicos directamente a las más altas autoridades; esto, como se ha podido demostrar, era una praxis legal más que aceptada por las altas instituciones coloniales, que venía arrastrada del derecho tradicional castellano del Antiguo Régimen. Sin embargo, estas prácticas, tales como las recomendaciones, favores y ventas de puestos públicos, llevadas hasta nuestros días, dentro del contexto del estado moderno a partir de las concepciones ilustradas del siglo XIX, son unánimemente consideradas como casos de corrupción. Estas actuaciones, que todavía hoy se dan y que aquejan muchas de las sociedades hispanas actuales, tienen una génesis enraizada en el derecho tradicional. Por otro lado, y de acuerdo con las teorías foucaultianas de la genealogía, se

http://www.biblioteca.tv/artman2/publish/index.shtml>, [consultado el 1 de octubre de 2018].

47 Ibid. 
puede inferir cómo parte de la génesis de las desigualdades raciales en América Latina es el resultado evolutivo del contexto político y social de la segunda mitad del siglo XVIII, el período aquí estudiado. De cara a las posteriores creaciones de las patrias mexicanas, las élites criollas se apropiaron del poder y del discurso republicano, basando sus argumentos en la legitimación de sus orígenes europeos. Las cartas escritas por Ambrosio Melgarejo Santaella y los correspondientes resúmenes notariales que las acompañan son representativas de una compleja red de acontecimientos que estaban sucediendo en el momento que fueron escritas.

Para estudios futuros sería conveniente ampliar la investigación de otros elementos que también influyeron en la creación de un patriotismo criollo durante la segunda mitad del siglo XVIII y en el posterior proceso independentista. Una línea de estudio esencial sería el papel de los jesuitas en cuanto a la educación y al empoderamiento de los novohispanos. En las cartas de Ambrosio Melgarejo, las Temporalidades de los jesuitas es uno de los argumentos para mostrar al Rey su fidelidad a la corona; pero también se ha visto más arriba que la Compañía de Jesús estaba plenamente entregada a la causa de los criollos desde distintos aspectos sociales, especialmente el educativo. Por otro lado, mientras que Ambrosio Melgarejo desmanteló el Colegio jesuita de San Gregorio, del que se beneficiaban las clases indígenas, Antonio Eugenio, hijo de Ambrosio tomó las riendas del ya expropiado Colegio de San Ildefonso. Por consiguiente, el estudio de la influencia jesuitas podría considerarse como una línea de investigación con potencial relacionado con el estudio genealógico de las cartas aquí analizadas.

\section{BiBLIOGRAFÍA}

Bertrand, Michel, "Viejas preguntas, nuevos enfoques: la corrupción en la administración colonial española", Francisco Andújar Castillo y María del Mar Felices de la Fuente, El poder del dinero. Ventas de cargos y honores en el Antiguo Régimen, Madrid, Biblioteca Nueva, 2011, pp. 42-46.

Bobb, Bernard E., The viceregency of Antonio Maria Bucareli in New Spain, 17711779. University of Texas Press, 1962.

Diccionario universal de historia y geografía. Vol. 2, México, 1853.

Escudero, José A., El supuesto memorial del Conde de Aranda sobre la independencia de América, Ciudad de México, unAM, Instituto de Investigaciones Jurídicas, 2014.

Foucault, Michel, El orden del discurso. Traducido por Alberto González Troyano. Buenos Aires, Tusquets Editores, 1992. Título original: L'ordre du discours, 1970.

, "Nietzsche, la Genealogía, la Historia", Microfisica del poder, Madrid, Las ediciones de la Piqueta 1992, pp. 7-30. 
Garriga, Carlos, "El patriotismo criollo entre Nueva España y México", Clara García Ayluardo y Francisco J. Sales Heredial, Reflexiones en torno a los centenarios: los tiempos de la Independencia, Ciudad de México, Centro de Estudios Sociales y de Opinión Pública y Centro de Investigación y Docencia Económicas, 2008, pp. 83-128.

Hidalgo Pego, Mónica, Reformismo borbónico y educación. El colegio de San Ildefonso y sus colegiales (1768-1816), Ciudad de México, UNAM, Instituto de Investigaciones sobre la Universidad y la Educación, 2015.

Martínez, Mucio, Arbitraje, Puebla, Impr. de M. Corona y Cervantes, 1890.

Melgarejo Santaella, Ambrosio Eugenio, "Carta 1", MS Legajo 123 (2), Jesuitas, Ciudad de México, Archivo Histórico Nacional de Madrid, 1769.

“Carta 2", MS Legajo 123 (2), Jesuitas, Ciudad de México, Archivo Histórico Nacional de Madrid, 1769.

Ramos-Kittrell, Jesús A., Playing in the Cathedral: Music, Race, and Status in New Spain, Nueva York, Oxford University Press, 2016.

"Representación que hizo la Ciudad de México al rey don Carlos III en 1771 sobre que los criollos deben ser preferidos a los europeos en la distribución de empleos y beneficios de estos reinos”, 500 Años de México en documentos, http://www.biblioteca.tv/artman2/publish/index.shtml, 2008, [consultado el 1 de octubre de 2018].

"Resumen de Carta 1", MS Legajo 123 (2), Jesuitas, Ciudad de México, Archivo Histórico Nacional de Madrid, 1769.

"Resumen de Carta 2", MS Legajo 123 (2), Jesuitas, Ciudad de México, Archivo Histórico Nacional de Madrid, 1769.

Rujas Martínez-Novillo, Javier, "Genealogía y discurso de Nietzsche a Foucault", Nómadas. Revista crítica de Ciencias Sociales y Jurídicas 26, no. 2, 2010, pp. $1-15$.

Sanchiz, Javier y Víctor Gayol, "Seminario de Genealogía mexicana”, Geneanet, https://es.geneanet.org, [consultado el 1 de octubre de 2018].

Stoler, Ann Laura, “Archivos coloniales y el arte de gobernar”, Revista Colombiana de Antropología 46, no. 2, 2010, pp. 465-496.

Torales Pacheco, María Cristina, "Los jesuitas y la independencia de México: algunas aproximaciones”, Destiempos, no. 14, 2008, pp. 397-412. 
ANEXO I - (BORRADOR) Carta 1. Dirigida al Virrey de Nueva España, el Conde de Aranda. Ambrosio Eugenio Melgarejo Santaella. Archivo Histórico Nacional de Madrid. Legajo 123 (2).

Exmo. Señor.

Muy señor mío de mi mayor respecto: En oficio de [...], del que corre, me participó este Señor Virrey, daba quenta por mano de V. Exa. al Supremo Consejo extrahordinario, con los autos que le remití, y formé de su commision en horden ál extrañamiento, y ocupacion de Temporalidades, pertenecientes a los Regulares Jesuitas del Collegio de San Gregorio de esta Capital, recomendando el mérito especial, que contrate en el puntual desempeño de la expresada Commision: Lo que me franquea el afortunado motibo de manifestar ingenuo a V.Exa. Aquella verdadera inclinacion que he tributado siempre á las glorias de su nombre; I confiado en la notoria integridad, con que mira V. Exa a los buenos ves cuidares del Rey, y el Largo Tiempo de quasi 27 años que ha que tengo el honor de serlo fiel en esta Real Audiencia me atrevo a suplicar a la Grandeza de V. Exa. Le dispense un poderoso patrocinio a la Representación, que acompañó, para que deste modo, elevándose la pequeñez de mis vergonzosos servicios en presencia del Monarcha, vean favorablemente despachados las humildes súplicas, que sobre el establecimiento de mis dos Hijos en sus respectivas carreras le hago rendidamente a su soberana dignación.

Dios Nuestro Señor Guarde la importante vida de V. Exa. En su mayor Grandeza los Ms As que necesito O:

México y Marzo 28 de 1769.

Como. Señor

Ilm. De VC suma... VERIdo y VEG

Ambrosio Eugenio

Melgarejo y Santaella 
ANEXO II - (BORRADOR) Resumen de Carta 1. Probablemente realizada por un notario de la corte virreinal. Archivo Histórico Nacional de Madrid. Legajo 123 (2).

El Oydor de la Audiencia de México Don Ambrosio Eugenio de Melgarejo y Santaella, suplica humildemente a V. M. Que si conforme a la recomendación, que hace el Virrey a fabor del especial mérito, que ha contrahido en el puntual desempeño de la Commision, que le confirió, para el extrañamiento, y ocupar las temporalidades de los Regulares Jesuitas del Collegio de San Gregorio; considera el compasibo ánimo de V. M. Ser digno, el que representa de alguna remuneracion; se sirva, de que recaiga en sus dos Hijos, el actual Rector de la Universidad Dr. Dn. Antonio Eugenio, y su hermano Dn. Joseph Ignacio de Melgarejo, y Lobera, confiriendo ál primero una de las Prebendas de esta Iglesia; y al seg.do Plaza Togada [...] En qualquiera de las Audiencias de estos Reynos, o la que fuese más de la suprema gratitud, y beneplácito de V. M. 
ANEXO III - (BORRADOR) Carta 2. Dirigida al Rey de España, Carlos III. Ambrosio Eugenio Melgarejo Santaella. Archivo Histórico Nacional de Madrid. Legajo 123 (2).

Don. Ambrosio Eugenio de Melgarejo, y Santaella, a [...] De V. M. Con la más profunda veneración, representa a su soberanía: Que en Villete de [...] del que corre, me participó el virrey, daba quenta ál Supremo Consejo extrahordinario por mano de su Presidente el Conde de Aranda.

Con los autos, de quinto practique en la Commision, que sobre el extrañamiento, y ocupación de Temporalidades pertenecientes a los Regulares Jesuitas del Collegio de San Gregorio de esta Capital, puso ál cuidado de mi pequeña conducta; mío especial mérito contrahido en el puntual desempeño de la expresada commision, recomendaba a V. M. Para que se sirviese de atender a is accensos: no dudando, el que su Real Clemencia, reciba benignamente las fieles dedicaciones de mi zelosa solicitud en debido obsequio del más exacto arreglamiento al Catholico espíritu de las justissimas, y bien premeditadas intenciones de V. M. Si logro afortunado esta distinguida honrar, como la he tenido de satisfacer todos aquellos asumptos, que me há cometido la Real Dignacion de V. M. En el dilatado discurso de quasi 27, años, que en esta Audiencia de México llevo ya de servicio y el relevante caracter, de que en el altissimo concepto de V. M. Sean acreedores mis afanes de alguna graciable remuneracion, suplico rendidamente a V. M. Que a efecto, de conseguir el natural consuelo dejase lustrosamente establecido a mis dos Hijos, se verifique aquella, confiriéndole la magnificencia de V. M. La Primera Prebenda vacante en el Choro de esta Iglesia al uno de ellos, quelo es, el actual Rector de la Real Universidad el Dr. Dn. Antonio Eugenio de Melgarejo, y Lobera; y a su hermano Dn. Joseph Ignacio, residente en essa Corte, Plaza Togada en qualquiera de las Audiencias de estos Reynos; o la que fuere de la mayor gratitud, y beneplácito de V.M. C. C. R,. P. Que Nro Señor los Ms As que la Monarchia ha menester: México, y Marzo 28 de 1769.

[...] Ambrosio Eugenio

de Melgarejo y Santaella 
ANEXO II - (BORRADOR) Resumen de Carta 2. Probablemente realizada por un notario de la corte virreinal. Archivo Histórico Nacional de Madrid. Legajo 123 (2).

México, y Marzo 28 de 1769

Duplicado $\quad N^{\circ} 359$

Don Ambrosio Melgarejo y Sta Ella.

Remite una Representación En que expone en México contrahido como comisionado a la ocupación el Colegio de San Gregorio y pide que en su atención se le dé Plaza de Indias a un Hijo suyo y prevenda en México a otro. 